
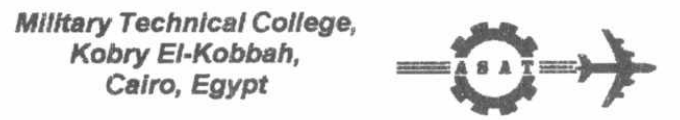

$9^{\text {th }}$ International Conference

On Aerospace Sclences \&

Aviation Technology

\title{
A PROPOSED RESIDUAL-STRESS MODEL FOR OBLIQUE TURNING
}

\author{
M. M. Elkhabeery
}

\section{ABSTRACT}

A proposed mathematical model is presented for predicting the residual stresses cause by turning. Effects of change in tool free length, cutting speed, feed rate, and the tersil strength of workpiece material on the maximum residual stress are investigated. Th residual stress distribution in the surface region due to turning under unlubricate condition is determined using a deflection-etching technique. To reduce the number $c$ experiments required and build the mathematical model for these variables, Respons Surface Methodology (RSM) is used. In addition, variance analysis and an experimente check are conducted to determine the prominent parameters and the adequacy of th model.

The results show that the tensile stress of the workpiece material, cutting speed, an feed rate have significant effects on the maximum residual stresses. The propose model, that offering good correlation between the experimental and predicted results, $i$ useful in selecting suitable cutting parameters for the machining of different materials.

\section{KEYWORDS}

Machining, Turning process, Residual stress, Cutting speed, Feed rate, Tool free lengtl

Associate Professor, Department of Production Engineering and Mechanical Design, Menoufia University, Faculty of Engineering, Shiben El-Kom, Egypt 


\section{1- INTRODUCTION}

Residual stress induced in the machined components plays an important role in affecting fatigue behavior of the machined material; hence, how to select the cutting parameters to reduce the residual stress is especially crucial. Residual stress is the result of various mechanical and thermal events which occur in the surface region during machining. It is usually found that the absolute value of the residual stress close to the surface is high and decreases continuously with an increase in depth beneath the machined surface eventually becoming vanishingly small. Residual stresses may be tensile or compressive and the stressed layer may be shallow or deep, depending upon the cutting conditions, work material, and tool geometry. It has been shown [1-3] that residual stresses may be compressive at the surface and tensile just below the surface or vice versa. Compressive residual stresses are generally improve component performance and life because they reduce service (working) tensile stresses and inhibit crack nucleation and propagation. On the other hand, tensile residual stresses can significantly increase service (working) stresses which can lead to premature failure of components [4-13]. Accordingly, it is very clear that the information concerning residual stresses in the machined surface region will be very valuable in the design and manufacture of parts.

The main objective of the present investigation is the properties of the residual stresses caused by oblique turning for different materials at different cutting conditions. In order to predict and improve the residual stresses of the machined surface, the main purpose of the present investigation is to determine, by the method of stress relief, the effects of change in cutting speed, feed rate, tool free length and tensile strength of work material on the residual stress and to build a proposed model for predicting the maximum residual stresses and choosing suitable cutting parameters for different materials.

\section{2- EXPERIMENTAL DETAILS}

In this investigation five different materials were used as the work materials. These materials and their chemical composition are listed in Table 1. These materials were selected because of their wide application as engineering structural materials in industry and their susceptibility to degradation when machined through surface and subsurface damage.

The work materials were first machined into ring-shaped workpieces having the dimensions shown in Fig.1. It is believed that residual stresses are induced in the surface region of the workpieces because of the machining involved in preparation, hence it was necessary to remove these stresses by annealing the worpieces. The stainless steel, steel-50, 7001-Al, 2024-Al, and brass workpieces were heated to $800,595,340,340$, and $260 \mathrm{C}^{\circ}$ for $3,6,2,2$, and 1 hours, respectively. The workpiece was clamped to a specially-made mandrel as shown in Fig. 1. 
Table 1: Chemical composition of workpieces materials in weight percent

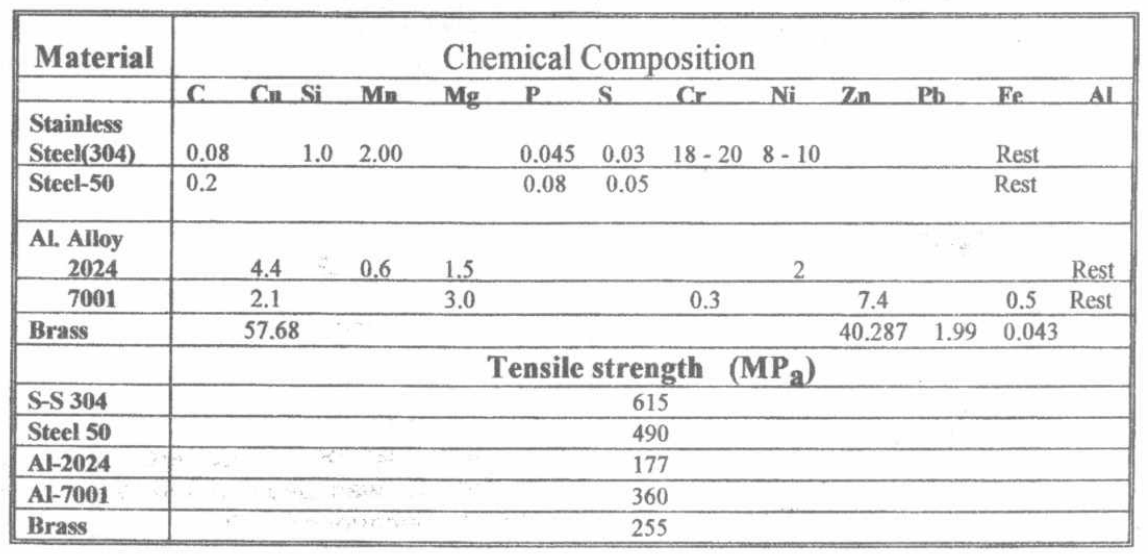

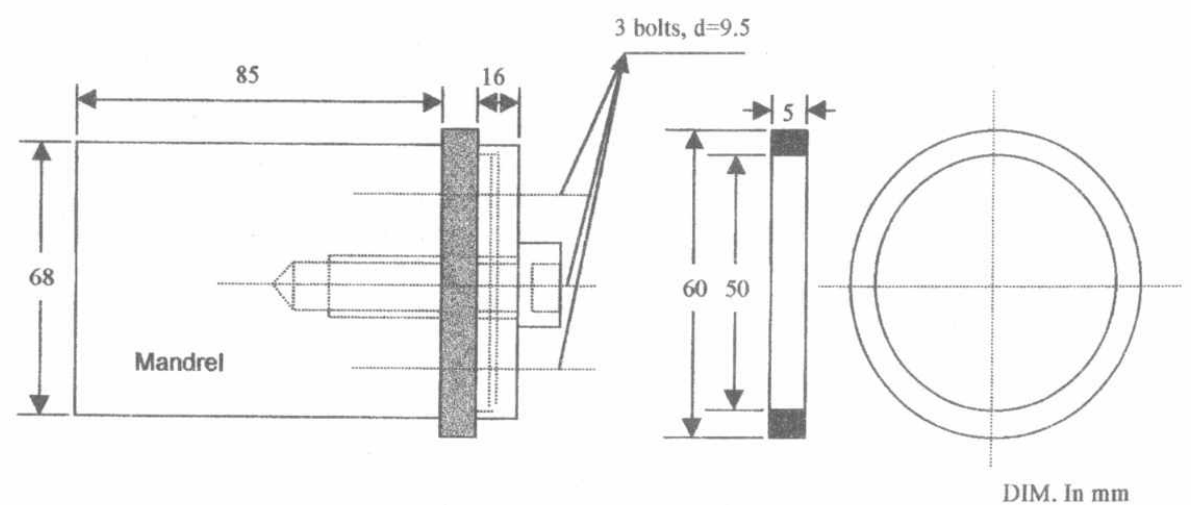

Fig. 1 Mandrel and workpiece

Turning experiments were conducted on a center lathe model DIZ 450x 1600, WMW, Germany. The tests were conducted over a wide range of turning conditions under unlubricated cutting conditions. In order to study the effect of cutting condition on the residual stress distribution thoroughly, only three turning cutting parameters were chosen; namely, cutting speed, feed rate, and tool free length. The cutting speed is known to have a significant influence on cutting temperature, strain rate, frictional processes, and surface region damage which, in turn, affect residual stress and then fatigue life. The second parameter used in this work was the feed rate because of its great effect on the chip formation, tool force components, and surface region damage which, in turn, affect residual stress. The tool free length was the third parameters because of its responsibility for of tool chatter during machining. This chatter has a great 
influence on the surface and subsurface characteristics. The fourth parameter used in this investigation to study the relationship between work material and the above three turning parameters on the residual stress distribution was the change in the workpiece tensile strength. Other parameters, such as, tool rake angle, clearance angle and depth of cut were hald constant throughout the investigation. The cutting conditions used in this work are summarized in Table 2.

Table 2: Summary of Cutting Conditions

\begin{tabular}{|c|c|c|c|c|c|c|}
\hline \multirow{2}{*}{ Parameters } & \multirow[t]{2}{*}{ Symbol } & \multicolumn{5}{|c|}{ Levels in code form } \\
\hline & & -2 & -1 & 0 & 1 & 2 \\
\hline Cutting speed, (m/min) & $x-1$ & 14.14 & 28 & 56 & 113 & 226 \\
\hline Feed rate, (mm/rev) & $x 2$ & 0.025 & 0.05 & 0.1 & 0.2 & 0.4 \\
\hline Tool free length, $(\mathrm{mm})$ & $\times 3$ & 10 & 20 & 30 & 40 & 50 \\
\hline Tensile strength, (MPa) & $x 4$ & 170 & 255 & 335 & 420 & 515 \\
\hline \multicolumn{2}{|l|}{ Tool rake angle (degree) } & \multicolumn{5}{|c|}{15} \\
\hline \multicolumn{2}{|l|}{ Clearance angle (degree) } & \multicolumn{5}{|c|}{8} \\
\hline \multicolumn{2}{|l|}{ Depth of cut $(\mathrm{mm})$} & \multicolumn{5}{|c|}{0.25} \\
\hline
\end{tabular}

In this work, the residual stress distribution in the surface region was determined using a laser optic deflection-etching which has been described elsewhere in the technical literature [8]. The electrolytic-deflection technique was used in the preference to the others because it gives the residual stress a continuous function of the depth beneath the machined surface and as an average over the entire specimen surface at any given circumferential section, which is thought to be more indicative of the true state of the machined workpiece than the siress at a single point on the machined surface (e.g., Xray diffraction measuring system is highly accurate) [8]

\section{3- PRESENTATION OF RESULTS}

The effect of the various parameters-including the cutting conditions and the tensile strength of workpiece materials--on the residual stresses is seen readily, and a model has been derived by RSM with the rotatable design. A considerable amount of data has been generated. The first eight experiments according to the experimental design matrix (Fig. 2) shows that the residual stress at the machined surface is low (tensile) and increases rapidly to a maximum (tensile ) value with an increase in depth beneath the machined surface. The tensile residual stresses then decrease gradually with a further increase in depth beneath the machined surface. Complete analysis of the data showed that the residual stresses continued to decrease across the section becoming either tensile or compressive at large depths.

The maximum residual stresses always occur beneath the machined surface rather than on the nearest layer to the machined surface; thus, making the part with this type of residual stress susceptible to sub-surface cracks and/or microcraks. 
It is now necessary to study the influence of the turning process parameters, used in this work, on the residual stress using a more adequate technique. The conditions of each machining test and its result of the maximum residual stress are presented in Table 3.

Cutting response (maximum residual stress) was developed in terms of the parameters used in the current work (cutting speed, feed rate, tool free length, and tensile strength of work material) using Response Surface Methodology (RSM) that was found to be a suitable technique for this work.

Table 3 : Experimental Design Matrix and Observation

\begin{tabular}{|c|c|c|c|c|c|c|c|c|c|}
\hline \multirow{2}{*}{$\begin{array}{l}\text { Exp. } \\
\text { No. }\end{array}$} & \multicolumn{2}{|c|}{ Cutting speed } & \multicolumn{2}{|c|}{ Feed rate } & \multicolumn{2}{|c|}{ Tool free length } & \multicolumn{2}{|c|}{ Tensile strength } & \multirow{2}{*}{$\begin{array}{l}\text { Maximum } \\
\text { residual stress } \\
\text { (Mpa) }\end{array}$} \\
\hline & $\begin{array}{l}\text { Code } \\
X_{1}\end{array}$ & $\begin{array}{l}\text { Actual } \\
\mathrm{V}\end{array}$ & $\begin{array}{c}\text { Code } \\
x_{2}\end{array}$ & $\begin{array}{c}\text { Actual } \\
\text { F }\end{array}$ & $\begin{array}{c}\text { Code } \\
X_{3}\end{array}$ & $\begin{array}{c}\text { Actual } \\
\mathbf{L}\end{array}$ & $\begin{array}{c}\text { Code } \\
X_{4}\end{array}$ & $\begin{array}{c}\text { Actual } \\
\mathrm{T}\end{array}$ & \\
\hline 1 & -1 & $(28)$ & -1 & $(0.05)$ & -1 & (22) & -1 & (Brass) & 62 \\
\hline 2 & 1 & (113) & -1 & $(0.05)$ & -1 & (20) & -1 & (Brass) & 88 \\
\hline 3 & -1 & (28) & 1 & $(0.20)$ & -1 & (20) & -1 & (Brass) & 79 \\
\hline 4 & 1 & (113) & 1 & $(0.20)$ & -1 & (20) & -1 & (Brass) & 142 \\
\hline 5 & -1 & (28) & -1 & $(0.05)$ & 1 & (40) & -1 & (Brass) & 76 \\
\hline 6 & 1 & (113) & -1 & $(0.05)$ & 1 & (40) & -1 & (Brass) & 149 \\
\hline 7 & -1 & (28) & 1 & $(0.20)$ & 1 & (40) & -1 & (Brass) & 198 \\
\hline 8 & 1 & (113) & 1 & $(0.20)$ & 1 & (40) & -1 & (Brass) & 221 \\
\hline 9 & -1 & (28) & -1 & $(0.05)$ & -1 & (20) & 1 & (Steel) & 350 \\
\hline 10 & 1 & (113) & -1 & $(0.05)$ & -1 & (20) & 1 & (Steel) & 385 \\
\hline 11 & -1 & $(28)$ & 1 & $(0.20)$ & -1 & (20) & 1 & (Steel) & 375 \\
\hline 12 & 1 & (113) & 1 & $(0.20)$ & -1 & (20) & 1 & (Steel) & 445 \\
\hline 13 & -1 & $(28)$ & -1 & $(0.05)$ & 1 & (40) & 1 & (Steel) & 270 \\
\hline 14 & 1 & (113) & -1 & $(0.05)$ & 1 & (40) & 1 & (Steel) & 348 \\
\hline 15 & -1 & $(28)$ & 1 & $(0.20)$ & 1 & (40) & 1 & (Steel) & 290 \\
\hline 16 & 1 & (113) & 1 & $(0.20)$ & 1 & (40) & 1 & (steel) & 311 \\
\hline 17 & -2 & (14) & 0 & $(0.10)$ & 0 & (40) & 0 & (Al-7001) & 140 \\
\hline 18 & 2 & (226) & 0 & $(0.10)$ & 0 & (30) & 0 & (Al-7001) & 350 \\
\hline 19 & 0 & (56) & -2 & $(0.025)$ & 0 & (30) & 0 & (Al-7001) & 198 \\
\hline 20 & 0 & (56) & 2 & $(0.40)$ & 0 & (30) & 0 & (Al-7001) & 330 \\
\hline 21 & 0 & (56) & 0 & $(0.10)$ & -2 & (10) & 0 & (Al-7001) & 183 \\
\hline 22 & 0 & (56) & 0 & $(0.10)$ & 2 & (50) & 0 & (Al-7001) & 220 \\
\hline 23 & 0 & (56) & 0 & $(0.10)$ & 0 & (30) & -2 & (Al-2024) & 38 \\
\hline 24 & 0 & (56) & 0 & $(0.10)$ & 0 & (30) & 2 & (Stainless) & 300 \\
\hline 25 & 0 & (56) & 0 & $(0.10)$ & 0 & (30) & 0 & (A)-7001) & 130 \\
\hline 26 & 0 & (56) & 0 & $(0.10)$ & 0 & (30) & 0 & (Al-7001) & 35 \\
\hline 27 & 0 & (56) & 0 & $(0.10)$ & 0 & (30) & 0 & (Al-7001) & 60 \\
\hline 28 & 0 & (58) & 0 & $(0.10)$ & 0 & (30) & 0 & (Al-7001) & 50 \\
\hline 29 & 0 & (56) & 0 & $(0.10)$ & 0 & (30) & 0 & (Al-7001) & 120 \\
\hline 30 & 0 & (56) & 0 & $(0.10)$ & 0 & (30) & 0 & (Al-7001) & 120 \\
\hline 31 & 0 & (56) & 0 & $(0.10)$ & 0 & (30) & 0 & (A)-7001) & 125 \\
\hline
\end{tabular}

In order to determine the independent, interactive and higher-order effects of the different variables on the residual stresses, a general form of polynomials that can be adopted to represent the response surface function is the second-order polynomial [14] :

Where:

$$
\text { Response } \quad \sigma_{\max }=b_{o}+\sum_{i=1}^{4} b_{i} x_{i}+\sum_{i=1}^{4} b_{i i} x_{i}^{2}+\sum_{i=1}^{4} \sum_{j \succ 1}^{4} b_{i j} x_{i} x_{j}
$$


$X_{i}$ is the independent variabies

$b_{0}, b_{i}, b_{i i}, b_{i j}$ are model coefficients

The values of these coefficients were obtained using a computer program. The less significant coefficients were eliminated from the analysis using the well known Student's t-test.

Also, to check the adequacy of the propcsed model, an analysis of variance was carried out using the F-ratio test.

Using the results presented in Table 3, the response surface for the maximum residual stress $\left(a_{\max }\right)$ as a function of the four parameters used in this work is cleduced as the following final equation :

$$
\begin{aligned}
\sigma_{\text {mam }}= & 91.392+33.735 X_{1}+24.895 X_{2}+95.2 X_{4}+40.567 X_{11}^{2}+45.31 X_{22}^{2} \\
& +29.71 X_{33}^{2}+21.598 X_{44}^{2}-38.063 X_{3} X_{4}
\end{aligned}
$$

The results of the student's t-test (Table 4) show that the cutting speed, the feed rate, the tensile strength of workpiece materials influence the residual stresses significantly. The final model is tested by variance analysis (F-test) [15], as shown in Table 5. Experimental verifications also being performed, the results are shown in Fig. 3.

Table 4: Values of coefficient and computed t-test of the response surface model

\begin{tabular}{|c|c|c|c|}
\hline & Coefficient & Computed T-value & Parameter \\
\hline & $b_{0}=91.39$ & 5.884 & \\
\hline & $b_{1}=33.73$ & 4.019 & $x_{i}^{*}$ \\
\hline & $b_{2}=24.89$ & 2.966 & $x_{2}^{*}$ \\
\hline & $D_{3}=0.459$ & 0.055 & $x_{3}$ \\
\hline & $b_{4}=95.20$ & 11.34 & $x_{4}^{*}$ \\
\hline & $b_{11}=40.57$ & 5.283 & $x_{11}{ }^{2^{*}}$ \\
\hline & $b_{22}=45.31$ & 5.901 & $x_{22}{ }^{2 *}$ \\
\hline & $b_{33}=29.71$ & 3.869 & $\mathrm{x}_{33^{2 *}}$ \\
\hline & $b_{44}=21.60$ & 2.813 & $x_{44^{2 *}}$ \\
\hline & $b_{12}=-2.1875$ & 0.213 & $x_{1} x_{2}$ \\
\hline & $b_{13}=0.0625$ & 0.006 & $x_{1} x_{3}$ \\
\hline & $b_{14}=1.1875$ & 0.110 & $x_{1} x_{4}$ \\
\hline & $b_{23}=1.3125$ & 0.128 & $x_{2} x_{3}$ \\
\hline & $b_{24}=-12.3125$ & 1.198 & $x_{2} x_{4}$ \\
\hline & $b_{34}=-38.0625$ & 3.704 & $x_{3} x_{4}$ \\
\hline
\end{tabular}
for the evaluation of residual stress

The standard critical value of the t.test: $\ell_{0.05 .26}=2.056$ 
Table 5: Analysis of variation (F-test)

\begin{tabular}{|cccccc|}
\hline Source & Sum of squares & degree of freedom & mean square & F-ratio \\
\hline First order term & 259498.20 & 4 & 64874.56 & 38.40354 \\
Second-order term & 102425.20 & 10 & 10242.52 & 6.063227 \\
Lack of fit & 63138.17 & 10 & 6313.817 & 2.737566 \\
Experimental error & 10135.71 & 6 & 1689.286 & \\
Total & 435197.3 & & & \\
\hline
\end{tabular}

* The standard value of the $F$ ratio for the significance level $o=0.05$ and degree of freedom 4 and 6 is $F_{0.05,(4,6)}=4.53$ and at degree of freedom 10 and 6 is $F_{0.05,(10,6)}=4.06$

In this model that obtained by the RSM method, the relationship between the residual stresses and significant variations are shown in Figs. 4-9.

Figures 4-6 show the effect of tool free length on the maximum residual stress in the surface region of components machined at various cutting speeds, feed rates, and tensile strength of work materials, respectively. It can be seen from Figs. 4 and 5 that, the residual stress in the machined surfaces are tensile for all the conditions shown in these figures. Also, it can generally be seen that an increase in the tool free length causes a decrease in the residual stress to a minimum value at tool free length of about $30 \mathrm{~mm}$. With a further increase in the tool free length, the residual stresses in the machined surface region increase again.

Figure 6 presents the variation of the maximum, near surface, residual stress with tool free length at different tensile strength of work material, showing an interaction between these two parameters. It can be seen that at low tensile strength of the work material, an increase in the tool free length causes an increase in the maximum residual stress. However, at high tensile strength of the work material, the maximum residual stress decreases gradually with an increase in the tool free length. Also, it can be realized that at low tool free length a decrease in tensile strength of work material causes a considerable reduction in the maximum residual stress so that a transition from tensile to compressive stresses occurs.

Figures 7 and 8 show the effect of the cutting speed on the maximum residual stress of machined surface at different feed rate and tensile strength of the work material, respectively. The residual stresses in the machined surfaces are tensile for all the conditions shown in these two figures. Also, it can be seen from figure 7 that the general trend is that an increase in the cutting speed causes a dramatic decrease in the maximum residual stress to a minimum value at a cutting speed of about $56 \mathrm{~m} / \mathrm{min}$. The stress then increases gradually with a further increase in the cutting speed. The general trend of Fig. 8 is similar to that of Fig. 7. Also, it can be seen that for a given cutting speed, an increase in the tensile strength of work material causes an increase in the residual stress in the subsurface region.

The variation of residual stress with the tensile strength of work material at various feed rates is shown in Fig. 9. It can be seen that the maximum residual stress increases with 
an increase in tensile strength of work material. It can also be seen for a given tensile strength of work material that the increase in feed rate from 0.025 to $0.10 \mathrm{~mm} / \mathrm{rev}$ causes a decrease in the maximum residual stress whereas the increase in the feed rate from 0.10 to $0.40 \mathrm{~mm} / \mathrm{rev}$ causes an increase in the maximum residual stress.

In general, the results show that an increase in tool free length, cutting speed and feed rate causes a decrease in the maximum residual stress to a minimum and then the maximum residual stress increases with a further increase in tool free length, cutting speed and feed rate. The residual stress generated in the machined surface region generally increases with an increase in the tensile strength of work material.

\section{4- DISCUSSION OF RESULTS}

It is not possible to advance a detailed rationale that can account quantitatively for the experimental results. However, a number of tentative suggestions will be made that may account, in part, for the trends observed.

It is evident $[3,8]$ that the residual stresses in the surface region of machined workpieces are generated principally by two facturs; namely, plastic deformation and material volume change associated with thermal gradients and metallurgical alterations in structure. The problem is complicated further because often these factors may act synergistically.

It is also well known that chip formation takes place by a process of shear in a zone known as "primary deformation zone" that extends from the tool cutting edge to the junction between the chip and the workpiece. If the mode of deformation (flow) of material in the zone is such that it extends below the nose of the cutting tool then it can lead to a deformed surface region. Additional deformation may occur from adhesion or sticking and develops between the tool flank and freshly machined workpiece surface. Heat generated by this plastic deformation in conjunction with heat generated in the primary and secondary deformation zones, can produce a significant increase in temperature in the surface region that can lead to volume change associated with thermal expansion and alteration in structure.

The mode of deformation in the primary deformation zone and the type of chip produced depend on the existing conditions of strain, strain rate and temperature that are themselves determined largely by cutting speed and tool geometry. Adhesion at the tool flank-workpiece interface depends primarily on the energy of adhesion that is, in turn, a function of the mechanical and physical properties of the metallic pair. The important physical quantities that may determine the final residual stress distribution appear to be the strain and temperature distribution generated in the surface region during machining. It is suggested $[7,8]$ that when machining, protrusion of the primary deformation zone below the nose of the tool produces a ploughing action that leads to surface region deformation and the generation of a work hardening and decrease with an increase in depth beneath the machined surface, eventually becoming vanishingly small. After passing of the cutting tool the loads will relax and residual stresses will be produced. It may be expected that the residual stresses at the surface will be high and decrease with an increase in depth beneath the machined surface. It is believed, however, that 
discontinuous chips lead to severe surface damage and plastic deformation that, in turn, causes the maximum residual stress to be high tensile. Increasing the above cutting condition; cutting speed from 14 to $56 \mathrm{~m} / \mathrm{min}$, feed rate from 0.025 to $0.10 \mathrm{~mm} / \mathrm{rev}$ and tool free length from 10 to $30 \mathrm{~mm}$ results in the continuous formation of chip which lead to considerable reduction in the resultant tool force and then in the surface damage and deformation. This, in turn, leads to a considerable reduction in the tensile residual stress that is developed beneath the machined surface.

The results of this investigation show that the maximum residual stress increases with a further increase in the tool free length, cutting speed and feed rate. These results are anticipated because of increasing the tool free length leads to an increase in surface damage and deformation that may be caused by tool chatter (vibration). Also, a further increase in either cutting speed and/or feed rate leads to an increase in the maximum residual stress. These results are also anticipated because an increase in either cutting speed, from 56 to $226 \mathrm{~m} / \mathrm{min}$, or feed rate from 0.10 to $0.40 \mathrm{~mm} / \mathrm{rev}$ leads to an increase in the resultant cutting force and a general increase in the depth of the deformed layer. This, in turn, causes an increase in the residual stress in the machined surface region. One of the most important characteristics associated with residual stress in component machined from high strength materials is the increase in the residual stress with increasing tensile strength.

\section{5- CONCLUSION}

A mathematical model is proposed for predicting the residual stresses caused by turning. Also, finding the optimum cutting conditions and how to control the residual stresses through this proposed mathematical model are very important for industry. According to this work, some conclusions may be summarized as follows:

1- A good correlation between the experimental and predicted results derived from the proposed model is exhibited in this work. Thus, using the proposed procedure, the optimum cutting conditions could be obtained to control the residual stress of other materials.

2- It is shown that the tensile stress of the workpiece material, cutting speed, and feed rate have significant effect on the residual stresses and there is an interaction between the tool free length and the tensile stress of the workpiece material.

3- Tensile residual stresses are generated in the machined surface region of different work materials turned under dry conditions. The residual stress is maximum near the machined surface and decreases in magnitude gradually with an increase in the depth beneath the surface.

4- The magnitude of the maximum residual stress generally decreases with an increase in tool free length, an increase in cutting speed and an increase in feed rate reaches to a minimum and then increases with a further increase in these parameters. The magnitude of the maximum residual stress generally increases with an increase in the tensile strength of work material. 


\section{REFERENCES}

[1] S. MITTAL AND C. R. LID, "A Method of Modeling Residual Stresses in Superfinish Hard Turning", Wear, Vol. 218, (1998), p. 21

[2] I.C. NOYAN and J. B. COHEN, "The Nature of Residual Stress and its Measurement", Sagamore Army Material Research Conference Proceeding, 28, 1(1981).

[3] C. R. LIU and M.M. BARASH, "Variable Governing Patterns of Mechanical Residual Stress in A Machined Surface ", ASME, Paper No.82-WA/Prod-8 (1982)

[4] M. FIELD, and J. F. KAHLESnd J. T. Cammett, " A Review of Measuring Method for Surface Integrity", Ann. CIRP. Vol. 21, (1972), p. 219.

[5] J. T. CAMMETT, "Residual Stresses-Measurements and Causes in Machining Processes", Annals of The CIRP, Vol. 31, No. 2, (1982), p. 491.

[6] M. M. Elkhabeery, and M. Fattoh, "Residual Stress Distribution Caused by Milling", Int. J. Mach. Tools Manufact. Vol. 29, No. 3, (1989), p. 391.

[7] A. B. SADAT and J. A. BAILEY, "Residual Stresses in Turned AISI 4340 Steel", Experimental Mechanics, Vol. 27, No. 1, (1987), p. 80.

[8] S. JEELANI and J.A. BAILEY, "Residual Stress Distribution in Machining an Annealed $18 \%$ Nickle Maraging Steel", Trans. ASME, J of Engineering Material and Tech., Vol. 180 , No. 2, (1986), p. 93.

[9] S. JEELANI and R. NATARAJAN, "Effect of Cutting Speed on Tool Rake Angle on Residual Stress Distribution in Machining 2024-T351 Aluminum Alloy - unlubricated Conditions ", J. Mater. Sci., Vol. 21,No. 8 , Aug. (1986), p.2705.

[10] M. H. EI AXIR, J. A. BAILEY, and M. M. EL-KHABEERY, " Effects of Selected Cutting Parameters On Fatigue Life, Maximum Residual Stress, and Surface Roughness: Part-I Unlubricated Conditions", Second Assiut University Int. Conf. On Mech. Eng. Advanced Tech. For Indus. Prod., March 2-4, (1999), p. 306-318.

[11] M. H. El AXIR, J. A. BAILEY, and M. M. EL-KHABEERY, "Effects of Selected Cutting Parameters on Fatigue Life, Maximum Residual Stress, and Surface Roughness: Part-II Lubricated conditions", Second Assiut University Int. Conf. On Mech. Eng. Advanced Tech. For Indus. Prod., March 2-4, (1999), p. 319-32.7.

[12] Z.-C. LIN, Y.-Y. LIN C.R.LIU, "Effect of Thermal Load and Mechanical Load on the Residual Stress of a Machined Workpiece”, Int. J. Mech. Sci. 33 (4), (991), p. 263278

[13] K. HUAFUH AND W. CHIH-FU," A Residual-Stress Model for The Milling of Aluminum Alloy (2014-T6)", J. of Material Processing Technology", 51, (1995), p. 87

[14] G. E. BOX and J. S. HUNTER, "Multifactor Experimental Designs", Ann. Math. Stat., 28, 1957, p. 195.Ann. Math. Stat. 28, (1957), p.195 (1957).

[15] J. A. Duncan, "Quality Control and Industrial statistics" Irwin Dorsey, Georgetown, 4th edn., (1974). 

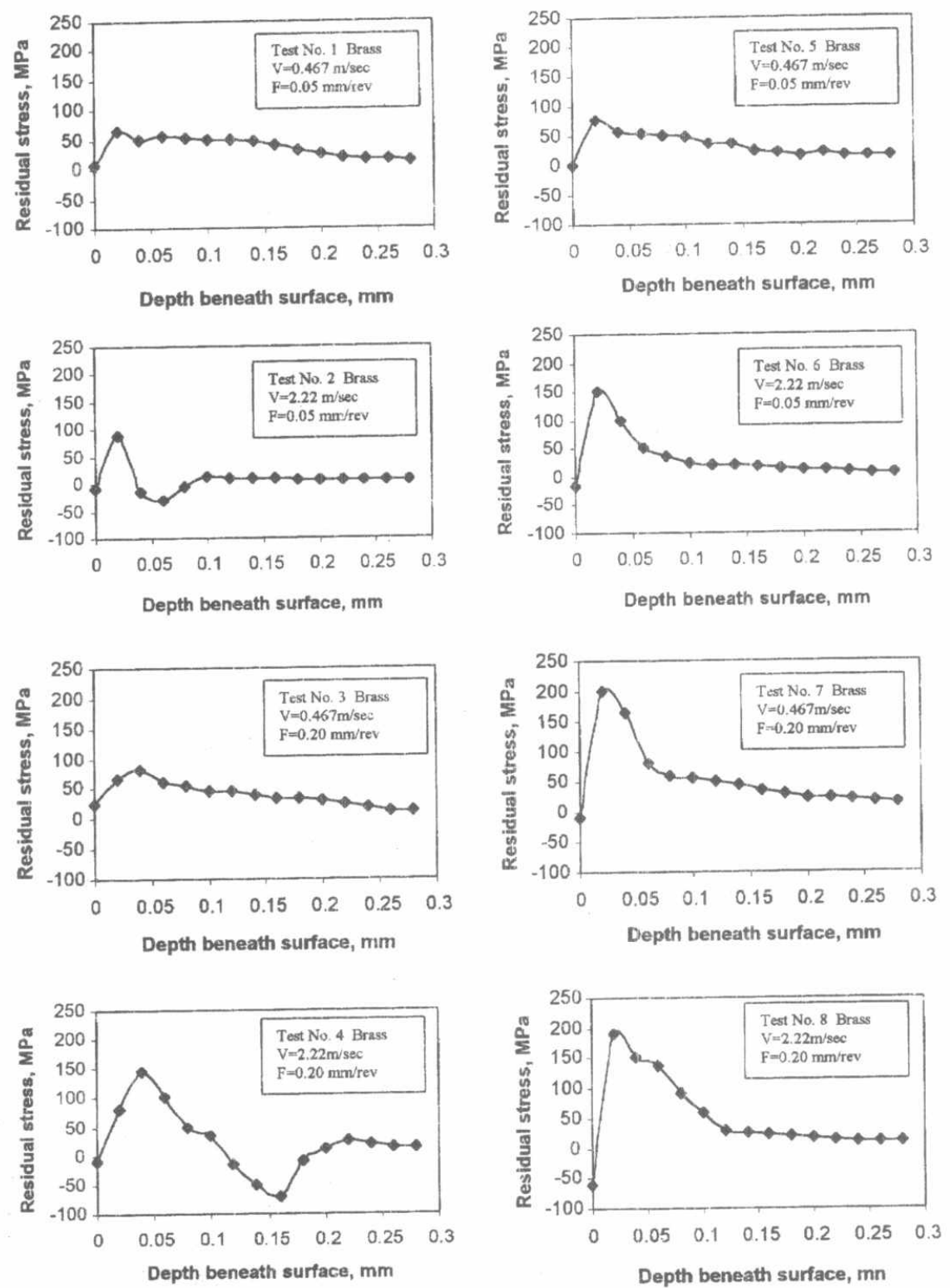

Fig. 2 Residual stress distribution in the machined surface region (According to the experimental design matrix) 


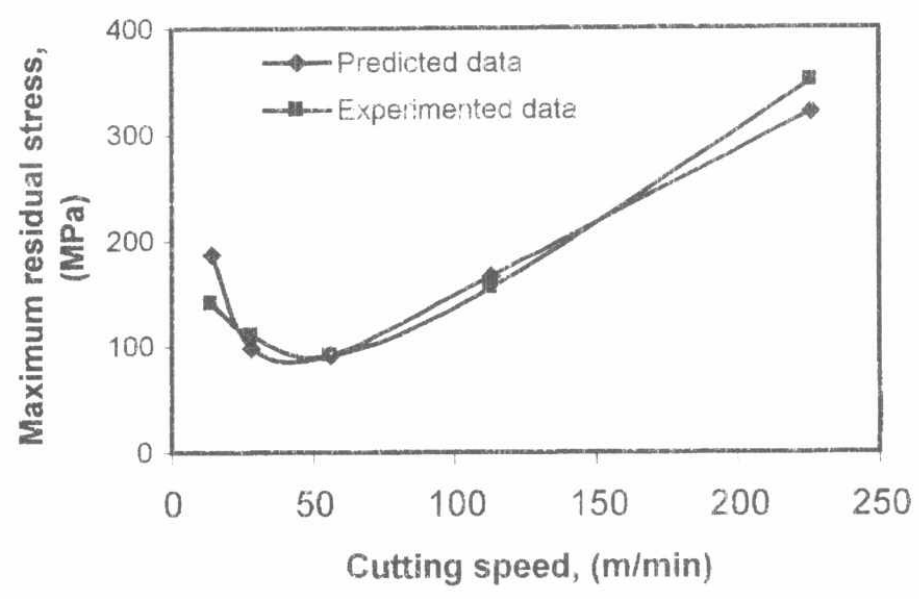

(a)

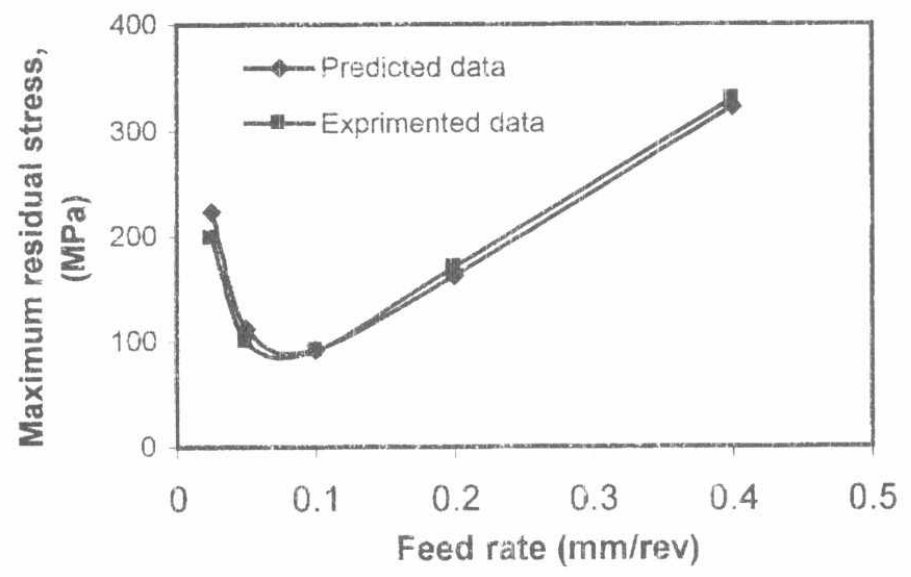

(b)

Fig 3 Comparison of predicted and experimental results for (a) varicus cutting speed, (b) various feed rate 


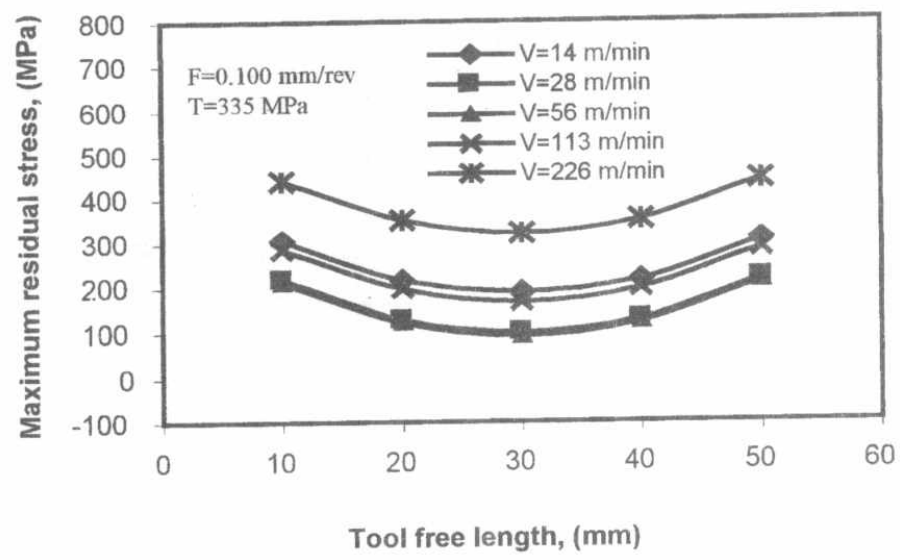

Fig. 4 Effect of tool free langth on the maximum residual stress for various cutting speeds $(\mathrm{m} / \mathrm{min})$

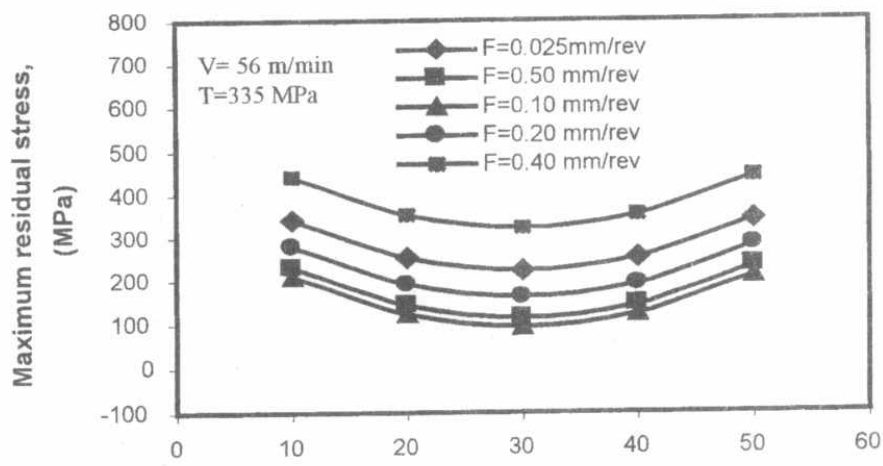

Tool free length, (mm)

Fig. 5 Effect of tool free langth on the maximum residual stress for various Feed rates $(\mathrm{mm} / \mathrm{rev})$ 


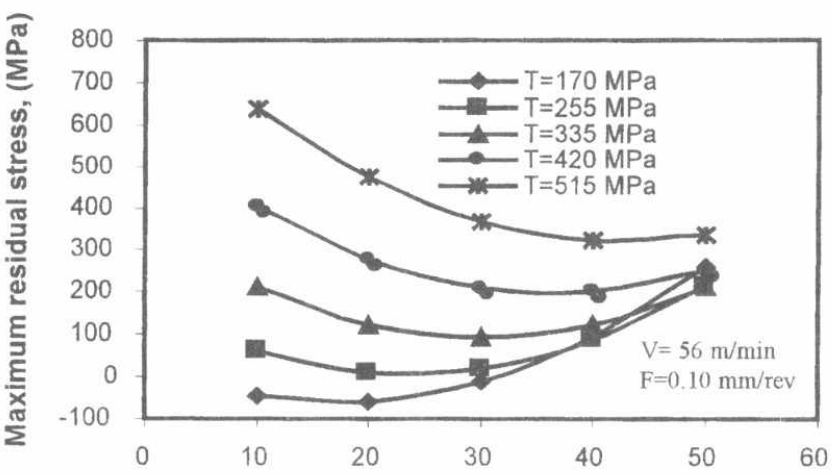

Tool free length, $(\mathrm{mm})$

Fig. 6 Effect of tool free length on the maximum residual stress for various Tensile strength of workpiece materials (Mpa)

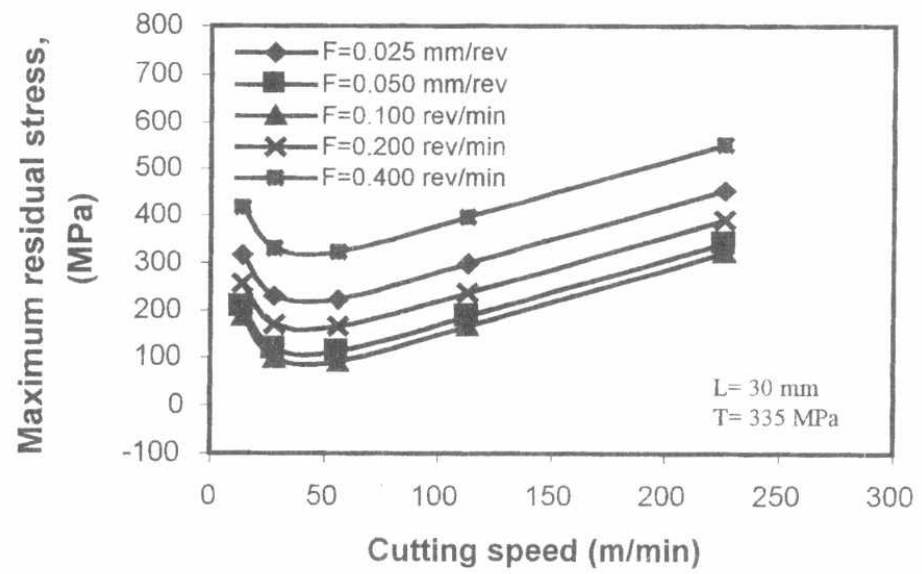

Fig. 7 Effect of cutting speed on the maximum residual stress for various feed rates $(\mathrm{mm} / \mathrm{rev})$ 


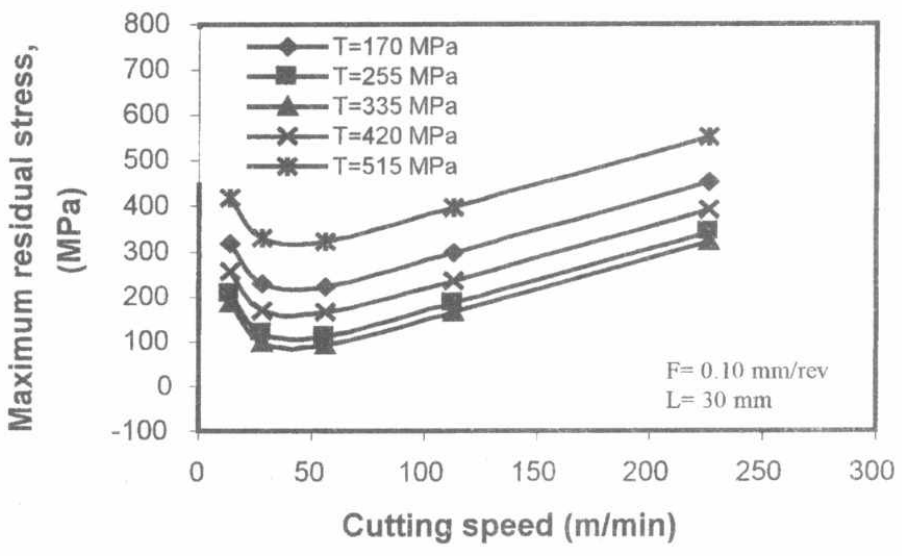

Fig. 8 Effect of cutting speed on the maximum residual stress for various Tensile stress of workpiece materials (Mpa)

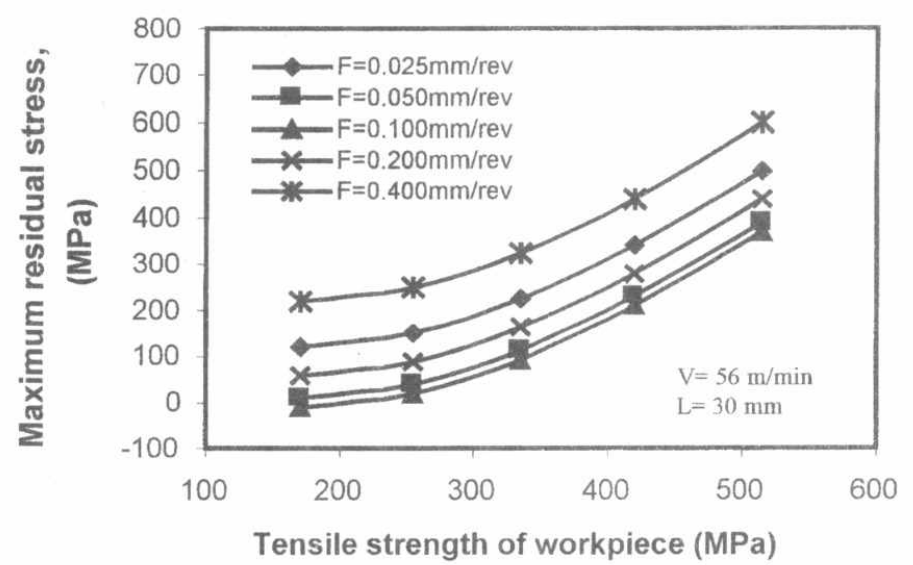

Fig. 9 Effect of tensile strength of workpiece materials on the maximum residual stress for various feed rates $(\mathrm{mm} / \mathrm{rev}$ ) 